\section{An Efficient Bifunctional Electrocatalyst for Methanol Oxidation}

\section{Jun Chen, Weimin Zhang, Zemin Dong, Gerhard F. Swiegers* and Gordon G. Wallace*}

Vapour Phase Polymerisation of Pyrrole and its Doping with 2. Preparation of PPy-2.

A thin film of ferric $p$-toluenesulfonate was coated onto an ITO slide electrode $(5 \mathrm{~cm} \times 2 \mathrm{~cm})$ via spin-coating $(1000 \mathrm{rpm})$ from a $10 \%$ (w/w) Fe(III) tosylate - ethanol solution $(2$ drops; $50 \mu \mathrm{L}){ }^{15}$ The ethanol was allowed to evaporate at $60-80{ }^{\circ} \mathrm{C}$ for $2-3 \mathrm{~min}$; a thin film of $\mathrm{Fe}$ (III) formed on the electrode surface. The electrode, overcoated with the Fe(III) film, was then exposed to pyrrole monomer vapour in a sealed chamber using the procedure described in reference 15 . The Fe(III) acts as an oxidant, inducing the pyrrole vapour to form polypyrrole on the surface of the electrode. After polymerisation is complete (15-30 min at room temperature), the electrode was left to air-dry for $1 \mathrm{~h}$. The electrode was then washed with a solution of acetonitrile containing $2(\mathrm{R}=\mathrm{Me})(10 \mathrm{mM})$. This solution removed the Fe(II) that was formed during the polymerisation and doped the polypyrrole with 2 . The polypyrrole layer shrinks noticeably during the washing. ${ }^{15}$ The UV-visible spectrum of the resulting PPy-2 film on ITO glass is depicted in Figure 3 and compared with that of an identically deposited PPy layer which had been washed with pure acetonitrile. As can be seen, the presence of 2 $(\mathrm{R}=\mathrm{Me})$ is indicated by the large and distinctive peak at $310 \mathrm{~nm}$. This peak persists, unchanged, even when the electrode is immersed for several days in methanol. For comparative purposes, VPP-polypyrrole containing only free 2,2'-bipyridine was separately prepared by washing with an acetonitrile solution containing 2,2-bipyridine (bpy) $(10 \mathrm{mM})$. As can be seen in Figure 4, the peak at $310 \mathrm{~nm}$ is noticeably absent from the UV spectrum of the resulting polypyrrole layer.

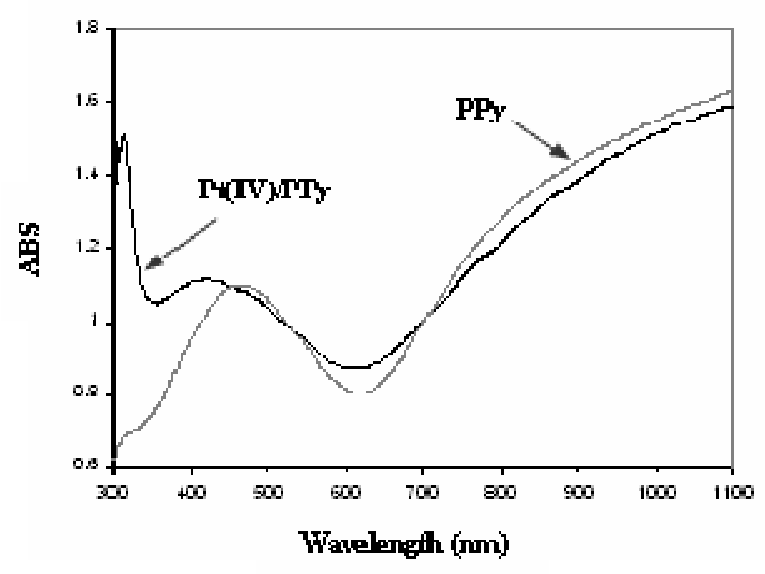

Figure 3. UV-visible spectra of PPy film on ITO glass electrode with and without incorporation of $\mathrm{Pt}(\mathrm{IV}) \mathrm{Me}_{2}(\mathrm{OMe})(\mathrm{OH})(\mathrm{bpy})$ into the polymer matrix

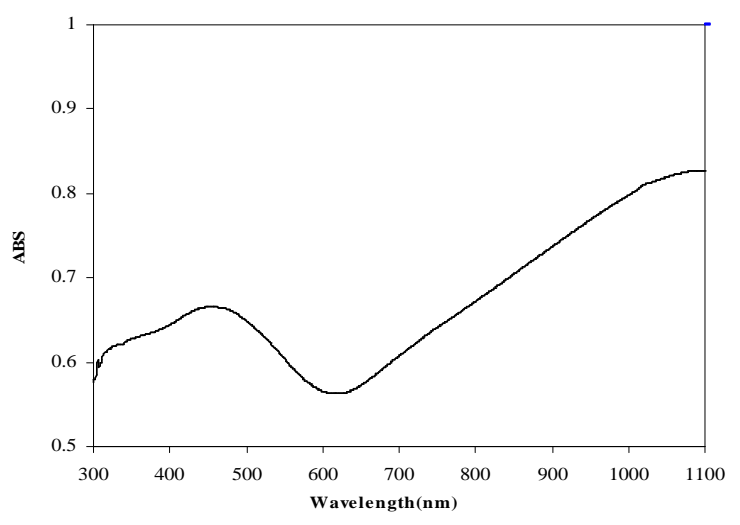

Figure 4. UV-visible spectra of PPy film on ITO glass electrode after incorporating free $2,2^{\prime}$ 'bipyridine into the polymer matrix. 